\section{A Nova Conformação Política do Mundo e o papel das Guerras do Golfo Pérsico e de Kosovo: uma leitura a partir da obra Império de Antonio Negri e Michael Hardt}

\section{New World Political Arrangement and the role of Kosovo and Persian Gulf Wars: a reading from the Empire of Antonio Negri and Michael Hardt}

\section{GILMAR ANTONIO BEDIN ${ }^{1}$ \& GABRIELI DE CAMARGO ${ }^{2}$}

Resumo: As transformações das últimas décadas, quando vistas em conjunto, estabelecem uma nova conformação do mundo. Essa nova conformação é extremamente complexa e permite várias leituras. O presente texto se preocupa em analisar a interpretação feita Antonio Negri e Michael Hardt na obra Império (2001). Nesse contexto, se preocupa em apresentar alguns pressupostos da obra referida (em especial a ideia de biopoder) e sua interpretação das guerras do Golfo Pérsico, de 1991, e de Kosovo, de 1999. Por fim, destaca-se que o objetivo do texto é tentar compreender as novas formas de governança global estabelecidas e como essa estrutura influencia e controla os fluxos do poder sobre os Estados. O método utilizado foi o método compreensivo e a técnica de pesquisa bibliográfica.

Palavras-chave: Direitos Humanos; Guerras; Poder.
Recebido em:

8 de Maio de 2018

Received on:

May 8, 2018

Aceito em:

22 de Novembro de 2018

Accepted on:

November 22, 2018

DOI: 10.12957/rmi.2018.34101

Abstract: The transformations of the last decades, when seen together, establish a new conformation of the world. This new conformation is extremely complex and allows for several readings. The present text is concerned with analyzing the interpretation made by Antonio Negri and Michael Hardt in the work Empire (2001). In this context, it is concerned with presenting some assumptions of the work referred to (in particular the idea of biopower) and its interpretation of the Wars of the Persian Gulf of 1991 and of Kosovo of 1999. Finally, it is emphasized that the objective of the text is to try to understand the new forms of global governance established and how this structure influences and controls the flows of power over states. The method used was the comprehensive method and the bibliographic search technique.

Keywords: Human Rights; Wars; Power.

\footnotetext{
${ }^{1}$ Doutor em Direito pela Universidade Federal de Santa Catarina (UFSC). Professor dos Programas de Pós-Graduação em Direito da Universidade Regional do Noroeste do Estado do Rio Grande do Sul (UNIJUÍ) e da Universidade Regional Integrada do Alto Uruguai e das Missões (URI). Endereço para correspondência: Rua do Comércio, 3000 - Universitário, Ijuí - RS, CEP: 98700-00, Brasil. E-mail: gilmarb@unijui.edu.br ORCID: https://orcid.org/0000-0001-9183-7065

${ }^{2}$ Mestranda em Direito pelo Programa de Pós-Graduação em Direitos Humanos pela UNIJUÍ. Bolsista FAPERGS (2017-2018). E-mail: gabrieli_camargo@ outlook.com. ORCID: https://orcid.org/0000-0002-8765-3973
} 


\section{Muralf INTERNACIONAL}

Mural Internacional

V. 9 |N. 1

JAN-JUN 2018

\section{Introdução}

As tentativas de compreensão do mundo atual são bastante desafiadoras. Uma dessas iniciativas, fundamental pela sua consistência e amplitude, foi formulada por Antonio Negri e Michael Hardt na obra Império (2001). Nessa obra, os dois filósofos internacionalistas, captam a essência da mudança paradigmática do imperialismo da realpolitik. ${ }^{3}$ De fato, revelam que, no mundo atual, é possível perceber o apogeu de uma estrutura política imperial - sem fronteiras, sem corpo material formado e com potencial global - que transforma a percepção e as ideias predominantes na sociedade internacional contemporânea e suas tendências colaborativas e pacifistas. A materialização desse poder pode ser encontrada nas guerras do Golfo Pérsico (1991) e Kosovo (1999). É que essas guerras revelam a referida forma de poder e sua forma de funcionamento, com destaque para seu grande alcance.

\footnotetext{
3 "Para além a referida tradição de estudos geográficos desenvolveu-se na Alemanha novecentista, um importante corrente de estudos históricos-políticos estreitamente associada ao movimento nacionalista alemão que impulsionou a unificação de 1871, sob a liderança da Prússia e do chamado "chanceler de ferro" - Otto von Bismarck. Dentro desse movimento destacaram-se os trabalhos dos historiadores Leopold von Ranke e Heinrich von Treitschke, que estão estreitamente ligados à difusão de dois neologismos no vocabulário político novecentista: a Realpolitik (política realista) e a Machtpolitik (política de potência)". (Fernandes 2003, p.227).
}

Mas o que essas guerras revelam? Qual é a natureza desses novos conflitos?

Para responder a tais perguntas, um ponto de partida possível é aproveitar as reflexões constantes da obra $O$ novo século (2009), de Eric Hobsbawm. Nessa publicação, o autor destacou, ao refletir sobre a total ilegitimidade da Guerra do Kosovo (1999), que “(...) as antigas regras de guerra e paz, que faziam distinção entre os conflitos internos e internacionais, já não se aplicam mais, e não parece nem um pouco provável que isso venha a mudar no futuro próximo" (Hobsbawm 2009, p.15). Além disso, lembrou também que a Guerra do Golfo Pérsico (1991), anterior à guerra de Kosovo, nos ensinou “...que a tecnologia avançada permite um poder de destruição muito mais preciso e seletivo" e que "as bombas inteligentes são capazes de escolher determinados objetivos e evitar outros", [o que torna possível uma nova forma de destruição: a destruição seletiva] (2009, p. 15).

Essas duas afirmações são fundamentais para quem está preocupado com a nova estrutura política do mundo e com a nova configuração das guerras. É que os referidos acontecimentos indicam claramente ao fim das chamadas guerras clássicas e a convergência entre violência e tecnologia. Esse novo 
cenário torna muito mais seletivo o uso da violência e permite a definição tópica de quem são os inimigos e quem devem ser protegidos. Portanto, permitem uma maior liberdade política para quem comanda a guerra e uma maior precariedade na aplicação das normas internacionais e na proteção dos direitos humanos.

\section{O Império na Contemporaneidade}

Os autores iniciam sua obra afirmando a existência de uma nova ordem mundial através de uma nova formação jurídica, de origem hobbesiana e lockeana, contratualista e de segurança. Essa nova ordem imperava a constituição da organização supranacional, em um futuro mundo globalizado. A Organização das Nações Unidas (ONU) nascia com o intuito de restabelecer a ordem, e através de suas instituições econômicas e de segurança, que para Hardt e Negri “(...) pode-se certamente analisar a estrutura jurídica da ONU em termos puramente negativos, e insistir no poder decadente dos Estados-nação no contexto internacional" (2001, p.22). Buscando restabelecer o sistema de Estados da modernidade, a ONU passava a ter certa soberania supranacional, a fim de regular suas ações no âmbito internacional e doméstico através de tratados e declarações constituintes - e é nessa fase (1945-1989) que o Império se formaliza e toma corpo "[n]as ambíguas experiências das Nações Unidas, o conceito jurídico de Império começa a ganhar forma" (Hardt; Negri, p.24). Desse modo,

Enquanto a hipótese hobbesiana salienta o processo contratual que faz surgir um novo poder supranacional unitário e transcendental, a hipótese lockeana concentra-se nos contra poderes que anima o processo constitutivo e apoiam o poder supranacional. Em ambos os casos, entretanto, o novo poder global é apresentado simplesmente em analogia com a concepção clássica do poder nacional soberano dos Estados. (Hardt; Negri 2001, p.25).

Muito se discutiu sobre o Império, de como a violência afetava a funcionalidade do novo paradigma. Desse modo, iniciaremos as abordagens sobre o Império -onde “(...) os processos de globalização já não são apenas um fato, mas também uma fonte de definições jurídicas que tende a projetar uma configuração única e supranacional de poder político" (Hardt; Negri, p.27). As relações internacionais entre Estados e Instituições políticas e socioeconômicas, passam assim, a ser regradas através do capital. Esse novo Império, estruturado juridicamente pela ONU e suas instituições como o Fundo Mundial Internacional (FMI), Organização Mundial do Comércio (OMC) e Banco Mundial (BIRD) sistematizam uma nova forma de 


\section{Muralf INTERNACIONAL}

imperialismo, um aperfeiçoamento de uma velha forma de manipulação de poder - a institucionalização do direito no meio internacional. Para os autores

Transformações jurídicas apontam com efeito, para mudanças na constituição material da ordem e pode mundiais. A transformação a que estamos assistindo, da lei internacional tradicional, que era definido por contratos e tratados, para a definição e constituição de um novo poder soberano e supranacional (e para uma noção imperial de direito), ainda que incompleta, nos dá uma estruturação na qual podemos ler os processos sociais totalizantes do Império (Hardt; Negri 2001, p.28).

De fato, essa mudança paradigmática transforma a constituição biopolítica da sociedade, no qual dedicaremos um subcapítulo ao demonstrar essa ideia. Voltando a ideia central sobre as características e funcionalidades, onde “(...) a concepção de Império ungiu categorias jurídicas e valores éticos universais, fazendo-os funcionarem juntos como um todo orgânico" (Hardt; Negri, p.28). Isso se remete ao período Imperial de Roma, onde o conceito de Império “(...) é apresentado como um conceito global, sob a direção de um único maestro, um poder unitário que mantém a paz social e produz suas verdades éticas (Hardt; Negri, p.28). Ademais, o Império pós-moderno continua dinâmico, ordenado e necessário.
Mural Internacional

V. 9 |N. 1

JAN-JUN 2018

Em consequência disso, os autores retomam a ideia de 'guerra justa' logo após as primeiras movimentações no golfo pérsico entre o Iraque e o Kuwait. Para Hardt e Negri "O conceito tradicional de guerra justa envolve a banalização da guerra e a celebração da luta como instrumento ético, ideias que que o pensamento político moderno e a comunidade internacional de Estadosnação repudiam com energia" (2001, p.30). Esse pensamento de guerra justa tradicional focal retorna ao período pósmoderno, onde a guerra passa a ser uma ação policial das potências em defesa aos Estados subjugados, “(...) um novo poder que pode exercer legitimamente funções éticas por meio de conflitos é sacralizado" (Hardt; Negri, p.30). Ademais, a guerra justa torna-se talqualmente justificável, como assinala os autores. Desse modo,

Dois elementos distintos combinam-se nesse conceito da luta justa: primeiro, a legitimidade do aparelho militar desde que eticamente fundamentado, e segundo, a eficácia da ação militar na conquista da ordem e da paz desejadas, A síntese desses dois elementos, pode, de fato, ser fator determinante na fundação de uma nova tradição de Império. Hoje o inimigo, como a própria guerra é banalizada (...) A Guerra do Golfo nos oferece, talvez o primeiro exemplo articulado dessa nova epistemologia do conceito (Hardt; Negri 2001, P.31). 
Seguindo sobre as discussões acerca a funcionalidade do Império, os autores desenvolvem um modelo de autoridade para esse novo paradigma, que já funciona em termos positivos, pois além de sistema é hierarquia “(...) construção centralizada de normas e produção de legitimidade de grande alcancem espalhada sobre o espaço mundial" (Hardt; Negri, p.31), conhecida também como 'governança sem governo', move todos atores em escala global. Com tal característica, o poder Imperial concentra-se no poder jurídico de governar sobre as exceções e sobre as capacidades de usar uma força - policial - para gerir a ordem, pois o "Império é formado não com base na força, mas com base na capacidade de mostrar a força como algo a serviço do direito e da paz (Hardt; Negri, p.33). Assim, visualizamos a 'necessidade' das intervenções internacionais no próximo subcapítulo, como finalidade para a estabilidade do ordenamento global, como reconhecimento de só um poder autônomo, central e estabelecido.

Sobre os valores universais que o Império apresenta, situa-se o direito imperial, abordado pelos autores “(...) uma espécie de técnicas que, fundamentadas num estado de permanente exceção e no poder de polícia, reduz o direito e a lei a problemas de pura eficácia?" (Hardt;
Negri, p.35). Os autores, procuraram entender $o$ processo constituinte do Império, que além de interagir com o direito internacional, perpassa por variadas mudanças nas leis administrativas na contemporaneidade. $\mathrm{O}$ direito de intervenção predominante nas ações internacionais intra-estados tem como principal foco evidenciar a instrumentalidade da ONU através de ações em manter a ordem internacional. "Agora as autoridades supranacionais que estão legitimadas não por direito, mas por consenso intervém em nome de qualquer espécie trivial de emergência e princípios éticos superiores" (Hardt; Negri, p.36). Dessa forma, o direito de polícia acaba sendo legítimo quando acionado por valores universais. Mas quem guiará esse movimento? De acordo com Hardt e Negri,

O Império está surgindo hoje como o centro que sustenta a globalização de malhas de produção e atira sua rede de amplo alcance para tentar envolver todas as relações de poder dentro de uma ordem mundial - e ao mesmo tempo exibe uma poderosa função policial contra novos bárbaros e escravos rebeldes que ameaçam sua ordem. O poder do império parece estar subordinado às flutuações da dinâmica do poder local e dos arranjos jurídicos parciais e utáveis (2001, p.3738).

No próximo item, será analisado quais são os principais elementos da gênese do referido ideal imperial, os meios por qual 


\section{Muralf INTERNACIONAL}

Mural Internacional

V. 9 |N. 1

JAN-JUN 2018 ele atua, além da produção social. Adiante da análise biopolítica, será possível também identificar as ações desse grande poder e de seus controles.

\section{O Biopoder para Hardt e Negri}

Partindo da ideia inicial de biopoder de Michel Foucault, os autores retomam um debate sobre como o biopoder se articula na complexidade do Império. Assim, a obra de Foucault reconhece uma transição histórica do período, da sociedade disciplinar para a sociedade de controle. Para descrever o momento em que a sociedade disciplinar surge, citam a primeira fase capitalista de acumulação, que conduziu a ideia sobre esse paradigma de poder, e a sociedade de controle nos limites da modernidade e início da pós-modernidade. Desse modo, nos concentramos na ideia da sociedade de controle para explorar as contribuições dos autores, em que "(...) o poder agora é exercido mediante máquinas que organizam diretamente $o$ cérebro e os corpos no objetivo de um estado de alienação independente do sentido da vida e do desejo de criatividade (Hardt; Negri, p.42). Nesse sentido, essa transição entre a sociedade de disciplina ao controle, perpassa na ideia da vida comum fora das estruturas institucionais, sendo mais flexíveis e flutuantes.
Por consequência dessas mudanças, o paradigma da biopolítica se torna a ideia de poder, onde "(B)iopoder é a forma de poder que regula a vida social por dentro, acompanhando-a, interpretandoa, absorvendo-a e a reticulando" (Hardt; Negri, p.43), portanto - a produção e reprodução da própria vida - onde a sociedade de controle é capaz de adotar a biopolítica como área de referência exclusiva para a manutenção social. Nessa perspectiva, “(...) quando o poder se torna inteiramente biopolítico, todo corpo social é abarcado pela máquina do poder e desenvolvido em suas virtualidades" (Hardt; Negri, p.43). A sociedade, por consequência desse mecanismo, de um só poder regencial que permeia as estruturas e processos de desenvolvimento, se articula em um só corpo -através da subordinação real. Assim, o paradigma do poder no Império, perpassa tudo e todos, unificando os elementos da vida social. Desse modo, os autores estabelecem aspectos centrais sobre o Império:

O conceito de Império é a estrutura na qual a nova omniversalidade de sujeitos deve ser entendida, e é o objetivo cuja direção o novo paradigma de poder conduz. Aqui se abre um verdadeiro abismo entre as diversas fundações teóricas antigas da lei internacional (tanto em sua forma contratual e/ou na forma da ONU) e a nova realidade da lei imperial. Todos os elementos intermediários do processo ficaram, com efeito, à margem, 
de forma que a legitimidade da ordem internacional já não pode ser construída por mediações e tem de ser captada imediatamente em toda a sua diversidade. Já reconhecemos esse fato sob o prisma jurídico (Hardt; Negri 2001, p.45).

$\mathrm{O}$ que se estabelece, portanto, sobre a ideia do Império, é uma nova noção do direito no contexto globalizante, universal e sistêmico. O Estado e as tecnologias de polícia - institucionais legais - - como exemplificado anteriormente no primeiro subcapítulo, se tornam centrais nesse contexto. "O Império da lei continua a desempenhar papel central no contexto da transição contemporânea: o direito continua sendo eficaz e (precisamente por meio do Estado de exceção e das técnicas de polícia) se torna método" (Hardt; Negri, p.45). Ademais, o direito imperial representa apenas uma parcialidade do projeto constitutivo do novo ordenamento mundial, dado as limitações da área em conduzir essa dimensão de poder tão intrínseca em todos os seguimentos da bios humana no contexto contemporâneo.

Desse modo, Foucault, Deleuze e Guattari apresentam uma ideia pósestruturalista sobre o biopoder "(...) que renova o pensamento materialista e se apoia firmemente na questão da produção do ser social" (Hardt; Negri, p.47). A primeira análise sobre a ideia de produção social seria as transformações produtivas - não ocupados pela força de trabalho, mas sim, a mais-valia presente no trabalho intelectual - como os processos da comunicação. A segunda análise qualifica a ideia da dimensão social do trabalho na sociedade capitalista da comunicação, e como isso resulta em novos problemas na contemporaneidade, como os novos aspectos subjetivos identitários. Desse modo, os autores contemplam novas teorias que abarque essas problemáticas - como uma nova teoria do valortrabalho e da subjetividade do conhecimento - não especificados aqui por delimitação de espaço da pesquisa (Hardt; Negri, 2001). Nesse sentido, reconhecemos a biopolítica como um paradoxo do poder que envolve toda a vida social contemporânea, de máxima pluralidade e singularização, que com a globalização planetária, passa a reconhecer - através do prisma jurídico a universalidade dos imperativos morais que moldam essa sociedade do controle, “ (...) como um conjunto único e sistêmico, deve-se presumir um imediato pré-requisito (agindo num Estado de exceção) e uma tecnologia adequada, plástica e constitutiva (as técnicas de polícia $)^{4 "}$ (Hardt, Negri, p.45).

\footnotetext{
${ }^{4}$ Ver no próximo subtópico.
} 


\section{Muralf INTERNACIONAL}

Mural Internacional

V. 9 |N. 1

JAN-JUN 2018
As Guerras do Golfo Pérsico e Kosovar no Império

$\mathrm{O}$ marco histórico à qual se encontra essa obra de Hardt e Negri, contextualizam, com o que podemos citar da “(...) existência de uma nova ordem mundial" (Hardt; Negri, p.21). A Guerra do Golfo Pérsico em 1991 engenhada como uma ação conjunta em recuperar a soberania do Kuwait, além de restaurar uma estabilidade regional, acaba por ser a primeira ação da ONU desde a dissolução da União Soviética (Lupi, p.514). É nesse período, nos últimos anos da guerra fria, que recai aos Estados Unidos a responsabilidade do exercício do poder policial internacional, onde "(A) Guerra do Golfo foi a primeira vez que os Estados Unidos puderam exercer esse poder de forma plena" (Hardt, Negri, p.198). Sob uma agenda externa conservadora sobre a prerrogativa de Ronald Reagan - e a necessidade de um novo inimigo iniciam ao fim do século as investidas sobre os Estados falidos, sejam eles tomados pelo terrorismo, tráfico de drogas ou totalitarismo conservador (Dall'Agnol, Hendler, p.24). Assim, analistas marcavam um novo período, uma nova ordem global de uma estrutura supranacional limitando as ações de estados no sistema internacional como citam Hardt e Negri “(...) a Guerra do Golfo anunciou de fato, como disse
George Bush, o nascimento de uma nova ordem mundial" (2001, p.199).

De fato, não discutiremos as origens históricas das Guerras profundamente, por delimitação de espaço, mas sim, as implicações das intervenções internacionais nos dois conflitos em questão e como isso, remodela a ideia do direito à intervenção para Hardt e Negri. Sabemos que a Guerra do Golfo Pérsico, inaugurou um novo período quando a Grã-Bretanha enviou tropas ao Kuwait para barrar o avanço iraquiano na fronteira no início dos anos sessenta.

O alvo da ofensiva estadunidense já havia sido aliado. Durante a guerra Irã-Iraque, pareceu aos EUA que patrocinar o nacionalismo laico do partido Baath era uma forma de combater os efeitos da Revolução Islâmica iraniana e impedir o aumento da tensão no Oriente Médio, de onde vem parte importante do petróleo importado pelos EUA. Terminado o conflito, as pretensões territoriais do regime de Saddam Hussein levam-no à invasão do Kuwait (Lupi 2005, 517).

Com a tomada do poder por Saddam Hussein em 1979 e o avanço do nacionalismo do partido Baath, o Iraque se torna uma potência regional, por consequência da nacionalização do petróleo na década de setenta. Iniciando a década de oitenta com força militar, reivindica a posse sobre o território kuwaitiano, com o intuito de transformar o Iraque - uma espécie de líder na 
exploração petrolífera (Tripp, 2007). Nesse sentido, a guerra se estabeleceu em duas frentes, das acusações sobre o Kuwait pelo Iraque de exploração ilegal do petróleo na área de Rumaila (área fronteiriça entre os dois países) - além do avanço militar para a anexação da região pelo Iraque. O conflito em si, após o período de ocupação do Kuwait pelo Iraque, iniciou o processo de intervenção pelas forças de coalizão lideradas pelos Estados Unidos através das Nações Unidas pelo território da Arábia Saudita - sendo que Hussein, através de acordos diplomáticos, pragmaticamente se retiraria da região kuwaitiana se Israel, aliado estadunidense, se retirasse dos territórios do Líbano, Síria e Palestina (Trip, 2007).

Sendo os acordos diplomáticos malsucedidos, após o Iraque não se retirar do território, mesmo sendo estipulado pelo Conselho de Segurança, o Iraque de Saddam começa a sofrer as retaliações da frente de coalizão, sendo uma Guerra curta, de bombardeios intensos e de mísseis teleguiados por satélites. Na segunda frente, no início de 1992, o Iraque passa a retirar suas forças do Kuwait sem impor condições frente às influências internacionais no conflito - de embargos econômicos e ações militares em 1991 deferidas pela ONU resolução 660/90, encabeçada pelos Estados Unidos (Cervo, 2003).

\section{Muralf INTERNACIONAL}

A legitimação da ordem imperial, entretanto, não se pode basear na mera eficácia da sanção legal e do poderio militar para impô-la. Ela precisa ser desenvolvida pela produção de normas jurídicas internacionais que aumentem o poder do ator hegemônico de uma forma duradoura e legal (Hardt \& Negri 2001, p.199).

O outro conflito a qual buscamos apresentar as indagações sobre as intervenções internacionais é a Guerra do Kosovo, que alguns anos depois da primeira Guerra do Golfo, responde pela presença do ator hegemônico imperial, que além do poderio militar contaria com alguns imperativos normativos legais. Um conflito muito complexo, representou a derrota do nacionalismo sérvio, além de findar com a antiga Iugoslávia.

A guerra dos Bálcãs é o resultado de uma sucessão de fatos históricos que não podem ser desconsiderados na oportunidade em que se realiza uma análise da Iugoslávia, uma vez que se trata de uma escalada de eventos que tem um marco histórico em 1339, quando da derrota para os otomanos. O século atual não foge à regra, pois o território esteve sob o reino dos sérvios, dos croatas e dos eslovenos a partir de 1919 e da Iugoslávia desde 1929, tendo se tornado república comunista em 1949. A gestão do Marechal Tito, o responsável pela resistência aos nazistas durante a Segunda Guerra, iria marcar a trajetória política do País até o seu falecimento, ocorrido em 1980. O desaparecimento de Josip Broz 


\section{Muralf INTERNACIONAL}

Tito deixou o ambiente político instável, e as repúblicas passaram a disputar o controle do território (Fraquelli 1999, p.106).

É também no período da Guerra Fria, que essa região onde encontra-se $\mathrm{o}$ Kosovo se torna autônoma frente uma concessão constituinte da Iugoslávia, passando a mudar pragmaticamente quando Slobodan Milosevic do Partido Comunista sobe ao poder em 1989 e retira a autonomia kosovar conquistada anos antes. Em 1992, a grande maioria da população kosovar opta pela separação através do voto, indicado a vontade do povo, como acontecera no ano anterior pela autodeterminação nas independências da Croácia, Bósnia e Eslovênia. Assim, iniciou as crises na região e os massacres dos bósnios kosovares pelos sérvios. "Um acordo de paz foi firmado em 1995, mas os ataques do Exército de Libertação do Kosovo (ELK) aos sérvios levou Milosevic ao revide, com o envio de forças militares para fazerem frente ao ELK" (Fraquelli, p.106), sendo ao fim de 1998, o ELK inicia uma trégua, mas que se irrompe curtamente frente a tensão na região. Um acordo de paz firmado na França, propunha autonomia do Kosovo, retirada do exército sérvio e ingresso das tropas internacionais conduzidas pelas Nações Unidas elaborado em 1999 entre os albaneses kosovares e os iugoslavos,
Mural Internacional

V. $9 \mid$ N. 1

JAN-JUN 2018 acabou sendo rejeitado pelos sérvios, conduzindo assim à Guerra do Kosovo.

Nesse sentido, a intervenção da OTAN [Organização do Tratado do Atlântico Norte] supunha proteger os kosovares albaneses do extermínio, da deportação e de outros tipos de violência. O objetivo da intervenção foi justamente 'substituir a lógica do conflito e da destruição pela lógica da aceitação e cooperação com o outro', repetindo o que já havia acontecido na Bósnia, embora tentando evitar a fase da violência e do conflito (...) A OTAN deixou claro para os sérvios que sua recusa em assinar o acordo teria duas consequências, além do rompimento das negociações: o começo da campanha da OTAN no Kosovo e que nenhum soldado ocidental iria lutar no Kosovo, em vez disso, a campanha seria conduzida como uma canha aérea. $\mathrm{Na}$ verdade, este não foi um movimento diplomático muito inteligente: em negociações de paz o processo dificilmente pode ser conduzido de forma de deixar o outro lado sem opções - 'do nosso jeito ou de nenhum outro'. De qualquer forma, essa tem sido uma constante na política externa dos Estados Unidos, uma constante que tem feito da ação militar uma opção inevitável para os negociadores norte-americanos (Messari 2000, p.210).

Um ponto a qual devemos dar importância é a prática da 'intervenção' humanitária que ocorreu no Kosovo, no qual para Nogueira

(...) a despeito da ausência de critérios aceitos pelo conjunto da comunidade internacional e sancionados por 
instrumentos legais, e apesar da seletividade e irregularidade na sua aplicação, a prática da intervenção humanitária reflete a evolução do regime internacional de direitos humanos e a progressiva legitimação de várias modalidades de intervenção internacional - inclusive o uso da força (...) A decisão de intervir militarmente na Iugoslávia levantou objeções de duas ordens. A primeira pela OTAN para justificar a intervenção. Outra importante crítica dirige-se à 'unilateralidade' da decisão, ou mais precisamente, ao fato de ter sido tomada por uma organização de segurança regional sem a autorização do Conselho de Segurança da ONU, uma violação ao direito internacional (2000, p. 143 e 146)

Dessa maneira, Hardt e Negri categorizam a intervenção, como um novo alicerce de legitimidade em consequência das “(...) novas articulações do exercício da força legítima, onde durante sua formação, o novo poder tem de demonstrar a eficácia da sua força ao mesmo tempo em que são construídas as bases de sua legitimação" (p.53). Assim, o uso do novo poder legitimado é ligado à eficácia do uso da força. Desse modo, as intervenções não se concentram como eram na ordem antiga, mas sim, na intervenção universalizada - como o exercício da força física imperial nos variados territórios ao redor do globo. Os tipos de intervenção podem ser variados, militar, moral (principal linha de frente da intervenção imperial) ${ }^{5}$ e jurídicaeconômica, além disso, podem barrar certos tipos de ideologias que concorrem com o ideário imperial. Incisivos nas suas declarações, Hardt e Negri declaram que

A intervenção moral geralmente serve como primeiro ato que prepara o palco para a intervenção militar. Em tais casos, a ação militar é apresentada como ação de política sancionada internacionalmente. Hoje a intervenção militar é cada vez menos produto de decisões provenientes da velha ordem internacional ou mesmo de estruturas da ONU. Com mais frequência, ela é dita unilateralmente pelos Estados Unidos, que se incumbem de desempenhar a tarefa primária e, posteriormente, pedem a seus aliados que ponham em movimento um processo de contenção armada e/ou repressão do atual inimigo do Império. Esses inimigos são frequentemente chamados de terroristas (2001, p.56).

A principal concepção estabelecida para os autores, é que no período imperial, a relação entre prevenção e repressão é clara, mas quando o conflito é estabelecido, a repressão passa a se acentuar “(...) mediante ação preventiva que constrói novas relações (que serão

\footnotetext{
5 "O que chamamos de intervenção moral é praticado hoje por uma variedade de entidades, incluindo os meios de comunicação e organizações religiosas, mas as mais importantes talvez sejam as chamadas Organizações nãogovernamentais, as quais, justamente por não serem administradas diretamente por governos, entende-se que agem a partir de imperativos éticos ou morais" (Hardt; Negri 2001, p.545).
} 


\section{Muralf INTERNACIONAL}

Mural Internacional

V. 9 |N. 1

JAN-JUN 2018 consolidadas em tempos de paz, mas somente após novas guerras) e novas formações territoriais, políticas e funcionais à constituição do Império" (Hardt; Negri, p.56). Outra concepção é a ideia que as repressões ocorrem em decorrência a campanhas contra organizações, declaradas como máfias, ligadas principalmente ao comércio ilegal de drogas - criminalizando atividades e gerando alardes sociais, facilitando assim, seu controle. Mesmo que declarando essas atividades, num vasto sistema policial por meio do poder imperial, essas atividades não são normais, mas facilitam o ordenamento sistêmico por parte do império. "A guerra justa é efetivamente apoiada pela polícia moral, assim como a validade do direito imperial e seu funcionamento legítimo são apoiados pela necessidade e pelo exercício contínuo de poder policial" (Hardt; Negri, p.56). Por consequência desse ambiente sistêmico, os tribunais de justiça supranacionais seguem o exemplo, e os exércitos e Estados policiais constituem a regra do jogo, sustentando, produzindo e reproduzindo a construção do Império. Portanto, "as intervenções são sempre excepcionais, apesar de ocorrerem continuamente" (Hardt, Negri, p.57).
Assim, com o fim da guerra fria - os Estados Unidos ${ }^{6}$, como vislumbrados pela sua altivez nos conflitos descritos anteriormente, acabam por serem chamados para liderar, mas antes de tudo, desempenhar um papel: estabelecer na nova ordem imperial, a garantia e eficácia jurídica aos processos complexos do novo direito supranacional que surgia. E esse assento privilegiado de capitão policial que os Estados Unidos requerem e assumem através do poder imperial para a administração de um bem comum, cosmopolita - das liberdades, dos direitos humanos e das democracias - fazem, com que o país interviesse militarmente em diversos outros Estados no século XX. Essas guerras, do Golfo e Kosovar, demonstram, antes de tudo, a necessidade do alimento sistêmico desses países aos moldes imperiais atendendo o chamado da paz e da ordem, os imperativos imperiais que revelam-se nesse novo século. Sobretudo, com o fim da Guerra Fria e com o alinhamento dos Estados ao sistema imperial - pois estendem seu poder linearmente - sem subjugar países legítimos em sua soberania através de projetos constitucionais -, se articulam em seus

6 “Os Estados Unidos são a polícia da paz, mas só como última instância, quando as organizações supranacionais de paz demandam uma atividade organizacional e um complexo articulado de iniciativas jurídicas e organizacionais" (Hardt, Negri 2001, p.200). 
espaços, relações singulares e diversas nas redes de um espaço ilimitado. Ademais, para Hardt e Negri, esse ideal imperial que se desenvolve na contemporaneidade com a pósmodernidade, nasce com a expansão global do projeto constituinte dos Estados Unidos, no qual, o direito internacional passa a ser um métodoprocesso de negociação constante, de contratos entre as partes externas do sistema, envolvendo um processo institucional e constitutivo interno dos Estados, na qual "(A)s redes de acordos e associações, os canais de mediação e resolução de conflito, e a coordenação das várias dinâmicas de Estados estão todos institucionalizados dentro do Império" (Hardt, Negri, p.201).

\section{Considerações}

Muito criticado por diversos autores e ovacionados por outros ${ }^{7}$, o Império revela-se uma grande obra crítica aos acontecimentos na pós-modernidade. Sabendo-se que o ordenamento Imperial é fundamentado e formado pelos poderes de extensão global, e pelo seu regime biopolítico, alcança uma nova visão sobre os novos acontecimentos e problemáticas na virada de século para

7 Vem mais em Rush (2006). A teoria pós-moderna do Império (Hardt \& Negri) e seus críticos. Filosofia Política Contemporânea: Controvérsias sobre Civilização, Império e Cidadania.
Hardt e Negri. Mesmo sem visualizar as mudanças futuras, declaram uma mudança estabelecida no sistema imperativo globalizante. O Império, antes de tudo é uma obra de grande valor teórico, que traça antes de tudo, as mudanças estruturais na biopolítica contemporânea.

Sendo esse artigo, o resultado de algumas reflexões iniciais da obra dos autores, salientamos a importância dada à ideia do biopoder na sociedade. As ações provenientes do capital global e a funcionalidade no sistema. A interação que o poder do capital constrói na subjetividade das relações humanas, nas formações de identidades, e nas problemáticas internacionais. As intervenções, como citadas no Golfo (Iraque/Kuwait) e no Kosovo, talvez não tenham tanto apelo ao capital como esperávamos ao início do artigo, mas mostrou com as indagações dos autores, a primazia do sistema de polícia e controle moral na sociedade imperial em estabelecer um equilíbrio sistêmico e harmonioso. Mesmo sem se deparar sobre os acontecimentos futuros que foram importantes para basear as críticas dos autores mais contemporâneos, como as intervenções no Afeganistão e no Iraque (2001, 2003), as crises econômicas na Europa (Grécia, Espanha, Portugal), as antidemocráticas, movimentações populistas e 


\section{Mural INTERNACIONAL}

Mural Internacional

V. $9 \mid$ N. 1

JAN-JUN 2018

neofascistas em todo o globo, além da crise econômica em 2009 - a teorização sobre o Império se torna essencial, como uma via às ideias críticas nas ciências sociais.

\section{Bibliografia}

Cervo, A. L. (2003). 'A guerra de Bush contra o Iraque', Meridiano 47, Instituto Brasileiro de Relações Internacionais: Boletim de Análise de Conjuntura em Relações Internacionais, $\mathrm{n}^{\circ} 32 / 33$.

Dall'Agnol, G. F.; Hendler, B. (2016). 'A guerra do Iraque em perspectiva: um balanço da política neoconservadora e o ônus da guerra', InterAção, 11(11), pp.1737, [online]. Disponível em https://periodicos.ufsm.br/interacao/article/view/29397/16448 [Acesso em: 23 Out.018].

Fernandes, J. P. T. (2003). 'A Geopolítica Clássica Revisada', Revista Nação e Defesa, $2^{\mathrm{a}}$ série, $\mathrm{n}^{\mathrm{o}} 105$. [online]. Disponível em: http://hdl.handle.net/10400.26/1395 [Acesso em: 23 Mar. 2018].

Fraquelli, A. C. C. (1999). Kosovo, um elo militar para o século XXI. O Conflito nos Balcãs. Disponível em:

https://revistas.fee.tche.br/index.php/indicadores/article/download/1794/2162 [Acesso em: 23 Out. 2018].

Hardt, M.; Negri, A. (2001). Império. Tradução de Berilo Vargas. Rio de Janeiro: Record.

Hobsbawm, E. J. (2009). O Novo Século: Entrevista a Antonio Polito; tradução: Claudio Marcondes. São Paulo: Companhia das Letras.

Lupi, A. L. P. B. (2005). 'A Guerra do Golfo: Legalidade e Legitimidade', Novos Estudos Jurídicos, 10(2), pp. 513-536, [online]. Disponível em: <siaiap32.univali.br/seer/index.php/nej/article/view/410>. [Acesso em: 26 Mar. 2018]. 
Nogueira, J. P. (2000). 'A Guerra do Kosovo e a desintegração da Iugoslávia: Notas sobre a (re)contrução do Estado no fim do milênio', Revista Brasileira de Ciências Sociais, 15(44), pp-143-160.

Messari, N. (2000). 'Kosovo e o Ocidente: Exercícios na Construção da Identidade Ocidental', Contexto Internacional, 22(1), Rio de Janeiro, [online]. Disponível em: https://search.proquest.com/openview/fe80033ae995fc493c5902f092fa7a85/1?pqorigsite $=$ gscholar\&cbl=1936339 [Acesso em: 23 Out. 2018].

Rush, A. (2006). A teoria pós-moderna do Império (Hardt \& Negri) e seus críticos. Filosofia Política Contemporânea: Controvérsias sobre Civilização, Império e Cidadania. Atilio A. Boron, 1a ed. - Buenos Aires: Consejo Latinoamericano de Ciencias Sociales - CLACSO; São Paulo: Departamento de Ciência Política. Faculdade de Filosofia, Letras e Ciências Humanas. Universidade de São Paulo. Abril 2006. http://bibliotecavirtual.clacso.org.ar/ar/libros/secret/filopolconbr/Rush.pdf [Acesso em: 25 Mar. 2018].

Tripp, C. (2007). A history of Iraq. Cambridge: Cambridge University Press. 